performs sterilization at least as rapidly as a prevacuum type sterilizer. Typical sterilization temperatures and times are $132^{\circ} \mathrm{C}$ to $135^{\circ} \mathrm{C}\left(270^{\circ} \mathrm{F}\right.$ to $\left.275^{\circ} \mathrm{F}\right)$ with three to four minutes exposure time for porous loads and instruments. Instruments may be wrapped or in container systems during rapid sterilization because air is removed from the load completely, even in high-speed cycles.

Because an air leak does not effect the sterilizer's effectiveness, Bowie Dick monitoring may not be necessary with this process. ${ }^{3}$ Consequently, leak repairs can be scheduled at the convenience of hospital personnel, reducing equipment down time. ${ }^{3}$

Steam flush-pressure pulsing sterilizers have been used widely in industry for approximately seven years and now are available for use in hospitals. New sterilizers using this process cost approximately $\$ 25,000$ to $\$ 135,000$ depending on size, which is comparable to the cost of prevacuum sterilizers. Existing sterilizers can be upgraded to perform this new process, typically at half the cost of a new sterilizer. In today's healthcare facilities, where so much down time is attributed to steam sterilizer repair and where increased sterilization efficiency is an absolute necessity, this innovative technology should be considered.

\section{REFERENCES}

1. Joslyn LJ. Sterilization by heat. In: Block SS, ed. Disinfection, Sterilization, and Preservation. 4th ed. Philadelphia, PA: Lea \& Febiger; 1991:503-511.

2. Theta Corporation. Hospital Sterilization Systems Report 910. Middlefield, CT: Theta Corp.; 1990:203-349, 1054.

3. Mayworm Associates. The Joslyn process: a new sterilizer technology. Journal of Healthcare Materiel Management $1988 ; 6: 62,64$.

\title{
New AIDS Definition Increases AIDS Cases by 205\%
}

\section{by Gina Pugliese, RN, MS Medical News Editor}

The recently expanded AIDS definition resulted in an overwhelming 205\% increase in the number of reported AIDS cases in the United States in the first quarter of this year, compared with the same period in 1992. In the first quarter, 35,799 cases of adolescents and adults with AIDS were reported to the CDC, compared with 11,770 cases reported in the same period of 1992. The broadened definition accounted for about $60 \%$ of the reported cases. Experts from the CDC have said the large increase in cases was expected but isn't likely to continue.

As of January 1, 1993, the expanded definition includes indi- viduals with pulmonary tuberculosis, recurrent pneumonia, and invasive cervical carcinoma, in addition to those individuals with CD4 cell counts under 200. The increase in cases will result in a dramatic increase in demand for the already overwhelmed treatment and social services available. 